\title{
12 Creating a Library from a Locomotive Shed in Tilburg, the Netherlands
}

\begin{abstract}
The LocHal is both an imposing and inviting public meeting place located in the Spoorzone district in Tilburg in the south of the Netherlands. A former locomotive shed constructed in 1932 has undergone an intensive and splendid conversion involving excellent collaboration of several architectural firms and designers. It houses the Bibliotheek LocHal/LocHal Library of the Midden Brabant region which consists of six municipalities in the centre of the province of Noord-Brabant, and several other organisations. The new library has redefined its functions and provides a wide range of opportunities for users, not only facilitating access to information, but also ample opportunity for the creation of new knowledge and information as well as interactive and engaging activities. In addition to various areas for lectures and events, the library has a series of labs focusing on topics ranging from food to words where visitors can learn experientially and gain new skills. The LocHal library offers a unique learning and working environment where everyone is challenged to think outside the box, deviate from the beaten path, meet new people, learn and experiment. The new facility has proved popular with everyone and has been described as the beating heart of the district. ${ }^{1}$
\end{abstract}

Keywords: Library buildings - Design and construction; Public libraries - Netherlands; Engine houses (Railroads) - Remodelling for other use

\section{Introduction}

Tilburg is a city of approximately 220,000 inhabitants in the south of the Netherlands. The renovation and reopening of the LocHal complex (Figure 1) in 2019 catalyses the redevelopment of the 75 ha Spoorzone (https://www.bdp.com/en/ projects/projecten/n-z/Spoorzone-Tilburg/) in Tilburg, an area in the middle of the city previously used by NedTrain for the production and maintenance of trains. The building's design is the result of close collaboration between Civic Architects, Braaksma \& Roos Architectenbureau and Inside Outside, while the

1 The chapter draws heavily on the publications listed in the References and the content has been used with the permission of the authors.

2 Open Access. (2021 Jeske Boemaars, published by De Gruyter. (c))BY-NC-ND This work is licensed under the Creative Commons Attribution-NonCommercial-NoDerivatives 4.0 International License.

https://doi.org/10.1515/9783110679663-013 


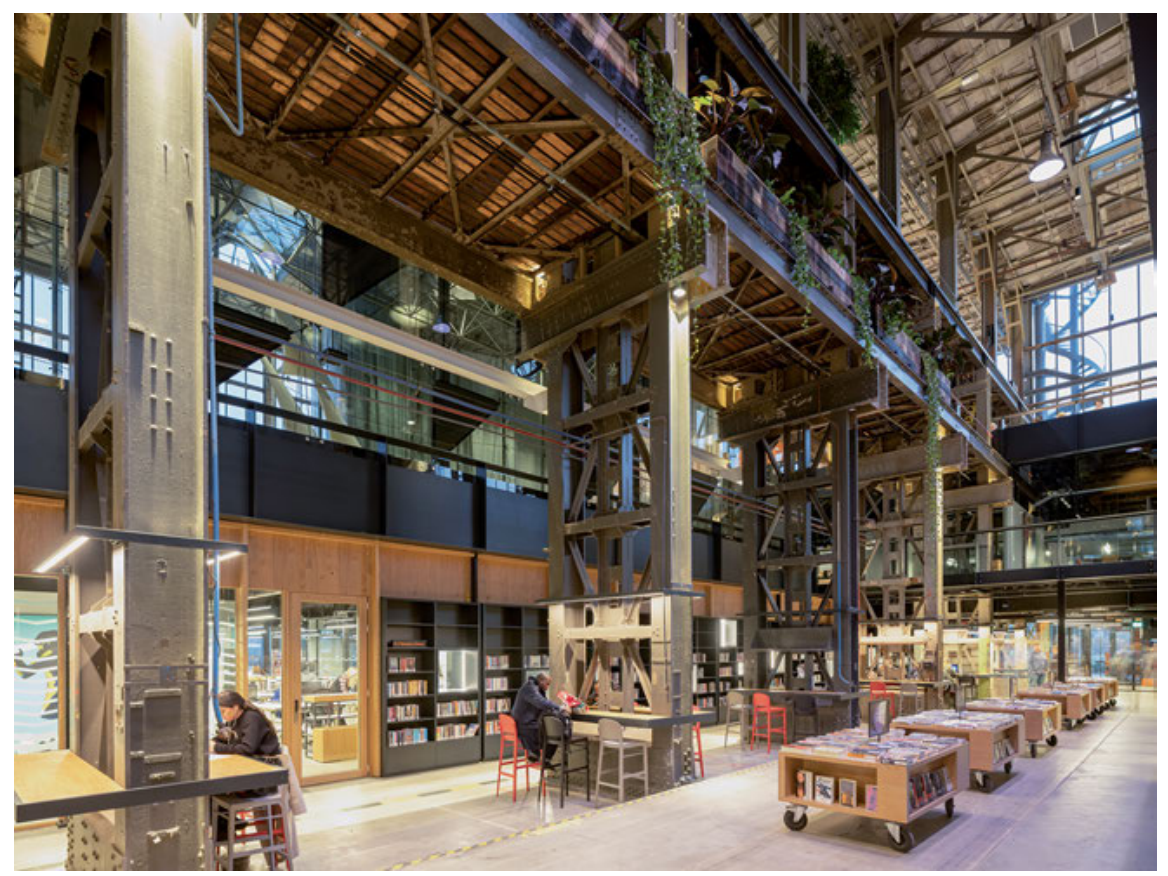

Fig. 1: The LocHal Library in a former locomotive shed. (C) Ossip Architectuurfotografie.

\section{Facts and Figures}

Name: Bibliotheek LocHal

Address: Burgemeester Brokxlaan 1000, 5041 SG Tilburg, Netherlands

Website: http://www.lochal.nl

Opening: January 2019

Builder: Binx Smartility

Architect: CIVIC architects https://www.civicarchitects.eu/; Braaksma \& Roos

Architectenbureau http://www.braaksma-roos.nl/bureau-braaksma-roos-

architectenbureau/; Inside Outside https://www.insideoutside.nl/; Mecanoo https://www.

mecanoo.nl/

Gross floor area: $11,000 \mathrm{~m}^{2}$

Main floor space: $6,000 \mathrm{~m}^{2}$

Collection size: 164,000

Staff: 50

Workstations: 320

Building costs: $€ 31,458,000$ 
engineering consultancy Arup advised on aspects such as sustainability, reuse and acoustic design. Mecanoo Architects was responsible for the interior design of the library spaces, various laboratories, the café and offices (Lomholt 2020).

In addition to the library, three other organisations are located in the LocHal: Kunstloc Brabant, Seats2meet Tilburg and CAST. Kunstloc (https://www.kunst locbrabant.nl/), is an advocate for art and culture in the province of Brabant and is in charge of curating the exhibition space. Seats2meet (https://www. seats2meet.com/en/locations/1213/Seats2meet-Tilburg-LocHal) rents out spaces for conferences and meetings. CAST is Tilburg's centre for architecture and town planning (https://www.castonline.nl/). The library and other tenants worked closely together with the municipality of Tilburg and the architects in the design and conversion process.

\section{The Locomotive Origins}

Nederlandse Spoorwegen/Dutch Railways (NS) was of great importance in the growth of the city of Tilburg at the beginning of the $20^{\text {th }}$ century. The LocHal occupies one of the original buildings, the locomotive shed constructed in 1932 (Figure 2) in the former railways yard which is now part of the urban renewal project in the Spoorzone. The locomotive shed is where the locomotives were built and maintained.

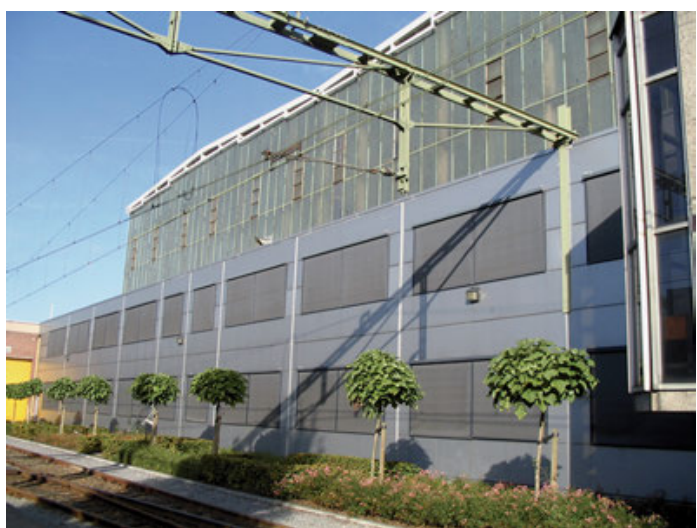

Fig. 2: The locomotive shed before restoration. (C) Rijksbouwmeester Atelier.

The large railways workshop employed many residents of Tilburg and played a crucial role in defining the city's profile. Tilburg is still known as a working-class city. The railyard was completely closed to the public until it ceased operations 
in 2011. Stories about the great trains and engines, the work undertaken, the machines, the sounds and even the smells have circulated through local families for generations. As the main workshop building, the LocHal (Figure 3) is the emblem and icon representing the past glory of the railways.

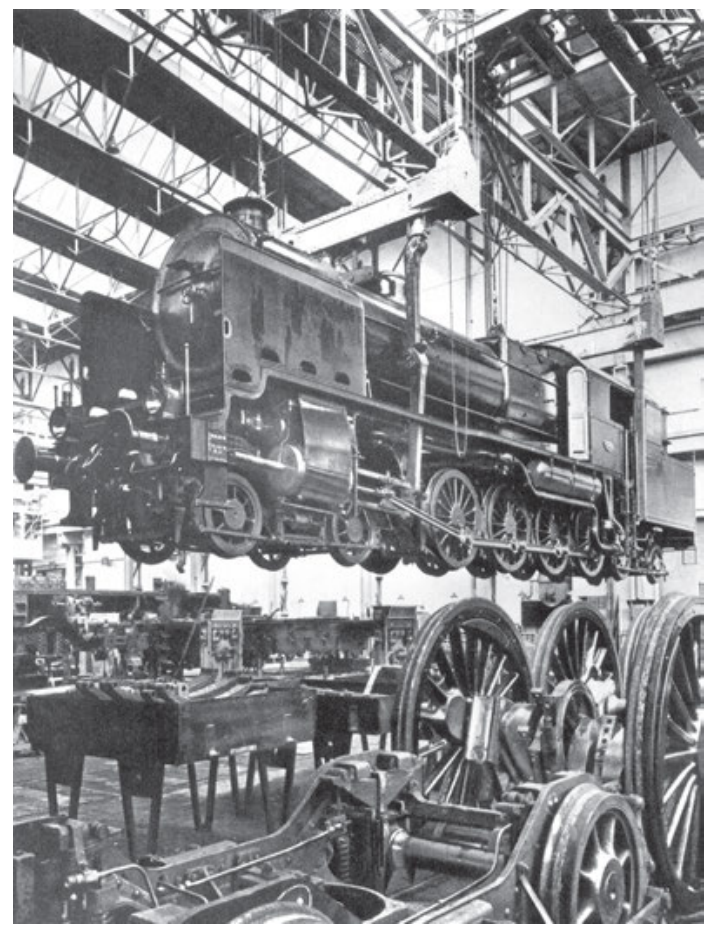

Fig. 3: LocHal as the main workshop building of the Dutch Railways.

The conversion of the locomotive shed into a public library has rendered it the living room of the city (Stephens 2019). The library, as one of the few community facilities freely open to all, has optimised its role and become the epicentre of the city, at the same time creating spaces for people to learn, interact with knowledge and each other, study, work and engage with the past. The building's previous story of blood, toil, tears and sweat is evoked and preserved for future generations. What has defined the city and its people has now become the heart of public life in a new form and can again define the development of the city in the next era.

The building connects and activates the surrounding infrastructure. Its location in the middle of a public transport node and the splendour of its construction have transformed the building into an attractive hub for engaging the community and sharing knowledge and information for the entire region. 


\section{A Public Place}

The sheer size of the new LocHal is its most impressive feature. It stands as a magnificent glass structure looming over the area. With a footprint of $90 \times 60 \mathrm{~m}$

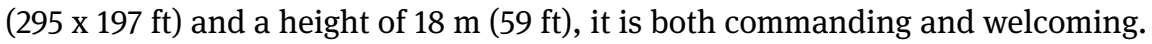
Accessibility, ease and transparency of use were the keynotes of the design with the central hall in the form of a covered city square leading and inviting users into the various areas. Imposing public reading tables double as a performance stage with an exhibition area and café. Wide staircases can be used to seat hundreds of spectators. With the customisable wooden seating elements, people can design their own spaces, forming group meeting places or quiet places for contemplation or undisturbed work. The huge glass façades expose the interior, attract all who pass by and allow for plentiful daylight (Figures 4 and 5).

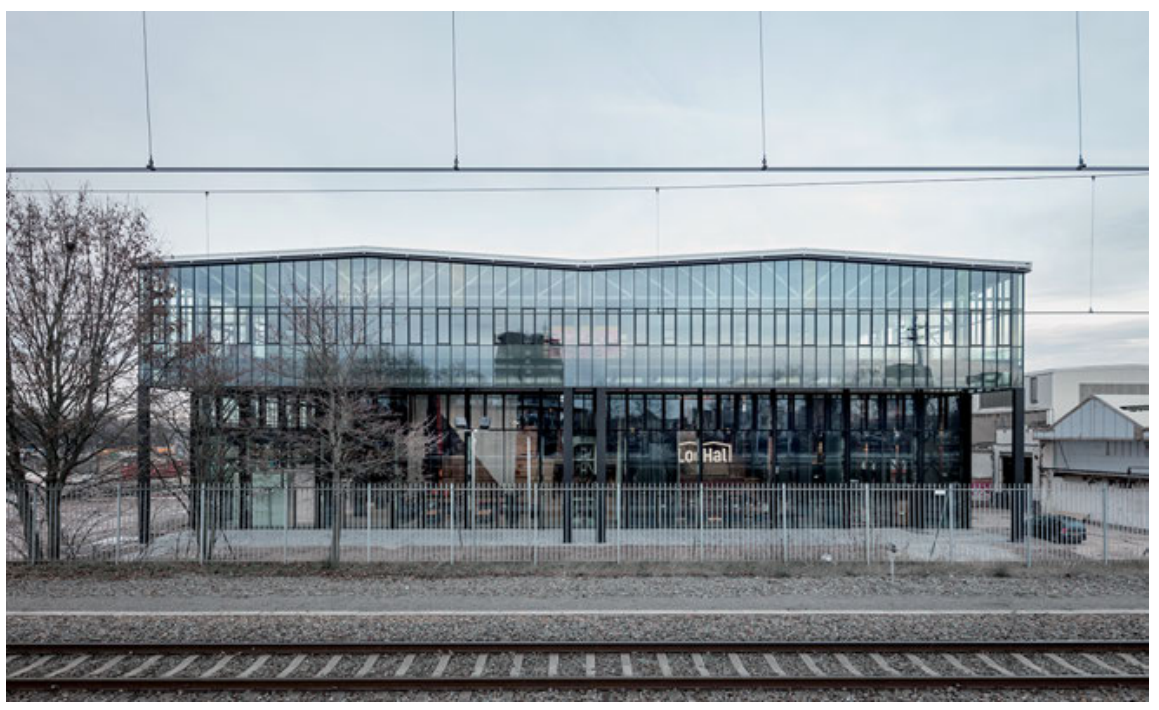

Fig. 4: LocHal library front view. (c) Stijn Bollaert and Civic Architects.

On the second floor, the gallery and stairways allow closer inspection of the historic glass walls as visitors browse the bookcases or make use of the quiet reading areas. One floor higher is a large balcony offering a panoramic view of the city (Lomont 2020). The history of the building is made tangible in the interior design. Characteristic historical elements are combined with contemporary oak and steel additions. The warm colour palette of reds and oranges enhances the interior and builds on past historical associations. 


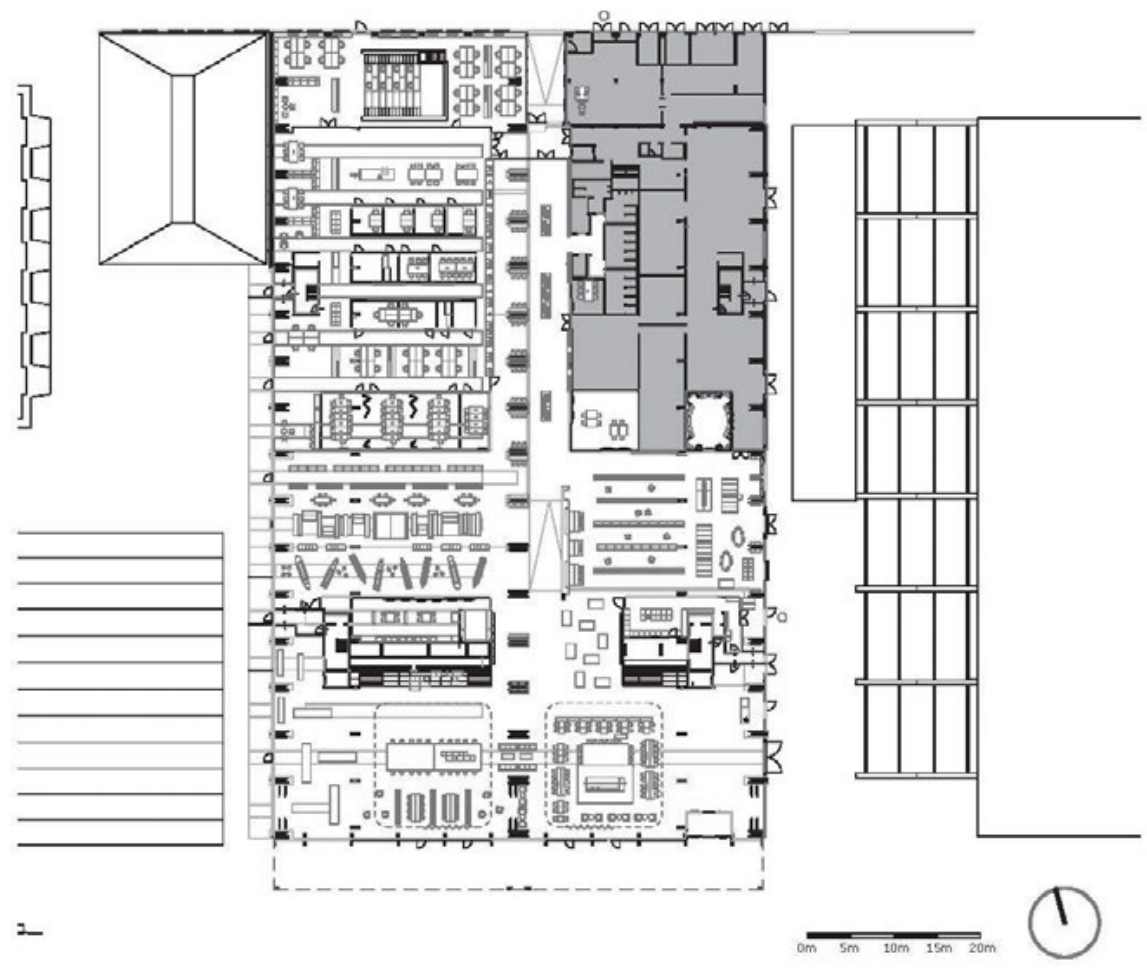

Fig. 5: Ground floor plan. (c) Braaksma \& Roos architects.

The new role of the LocHal has been much applauded and admired. "Traditional visitors, new visitors, students, entrepreneurs, people who come for lectures and for music; a real living room for everyone [...] You see and feel here what culture can do in the city and why it is so important," said Marcelle Hendrickx, City Councillor of Culture, Tilburg (Civic Architecture 2019, 23).

\section{Versatility Achieved by Textile Screens}

Amid all the openness, some events and activities may require privacy or a smaller space. Inside Outside designed six huge textile curtains which extend to ceiling height. They accentuate the scale of the building and at the same time provide the means of dividing the building into smaller defined separate areas and improving the acoustic properties (Figure 6). The ability to reconfigure spaces creates a range 
of different atmospheres supporting use of space for larger meetings, smaller collaborations and individual focused work. The interior layout and design ensure that the collection, the facilities and the manner in which they are used can be adapted to meet changing requirements.

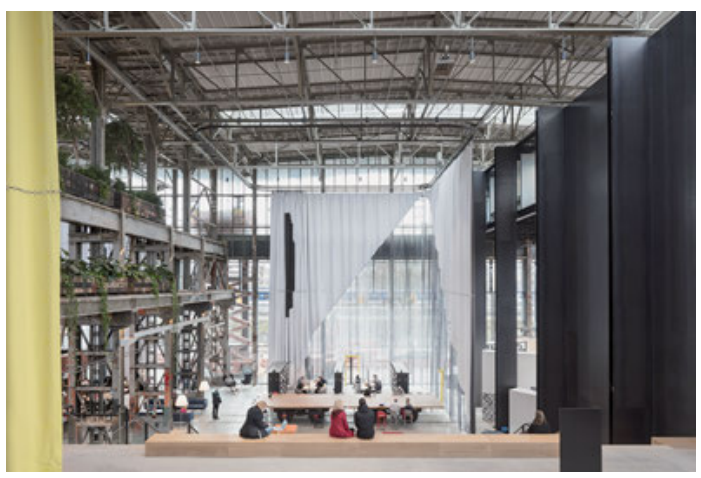

Fig. 6: Huge textile curtains. (c) Stijn Bollaert and Civic Architects.

The curtains can be remotely repositioned and moved to separate the meeting areas from the higher library floors, or across the staircases to create a small, semi-private auditorium. The largest curtain can be used to conceal the café or create the perfect backdrop for it.

When positioned in front of the windows on the south side of the building, the curtains soften the light that floods through the tall glass façades onto the central square. As the sunlight strikes the transparent surfaces, the curtains turn into tall cascades, becoming an integral part of the spacious interior landscape.

\section{A Library in the $21^{\text {st }}$ Century}

Not only has the building been transformed but the library itself has changed as well. In 2014 the library opened a greenfield or new project, called KennisMakerij/Learning or Knowledge-making (https://www.lochal.nl/werken-ontmoeten/ ruimtes/kennismakerij). It became a creative space where the library worked on innovative ways of sharing knowledge and stories alongside the traditional form of books. The experiences gained were incorporated into the new LocHal library concept.

Public libraries have been subject to evolution since they were first founded. They have been functioning as democratic organisations to educate people and fight illiteracy and as places for opinion sharing, public debate, leisure and artis- 
tic expression. In the age of digitisation and global information exchange, new approaches are needed which go beyond the introduction of new media and the fact that a library is a public place for gathering.

LocHal redefines the function of a library in today's digital era. The new library provides ample opportunity for the creation of new knowledge. The building's design inspires visitors to discover something unexpected and to have meaningful encounters. Curatorship has become as important as the books themselves: interactions with real life experts offer deeper, richer ways to acquire knowledge and obtain information. The new role is facilitated by the architecture. The LocHal offers a unique learning and working environment with workplaces in the public area, private study rooms for one or two people or rooms for meetings. In addition to various areas for lectures and public events, the library has a range of labs where visitors can learn and gain new skills. The thematic labs, with their remarkable design, can be found throughout the building: a FoodLab, WoordLab/WordLab, DigiLab, GameLab, TijdLab/TimeLab and FutureLab.

The many library events held reflect the city and its residents and are initiated by the library itself but more frequently by the library's visitors and partners. The activities take place in the open space, in the KennisMakerij/Learning or Knowledge-making area, or the StemmingMakerij/Dialogue or discussion forum (https://www.lochal.nl/werken-ontmoeten/ruimtes/stemmingmakerij) or in one of the six labs. Experimentation is encouraged and celebrated. People work together, learn from each other and develop ideas. Traditional roles like those of student or teacher are set aside as a participant may be a student one moment and a teacher the next. The library's event programmers support and facilitate the access to knowledge and actively connect communities and individuals.

IFLA President Christine Mackenzie has commented on the concepts developed in the LocHal Library.

LocHal in Tilburg in The Netherlands had its official opening last weekend ... 5,000 people came through the door. I was there on Sunday, and there were 1,800, so it must have been really busy on Saturday. The City provided the Library service, Bibliotheek Midden-Brabant, with an historic building, but not your normal hand me down - this was a railway locomotive workshop - a huge great shed with heavy duty cranes that were used to lift the locomotives to repair them. Other unique features are floors with the railway lines still there, massive steel beams, a lot of windows as well as an excellent position right next to the railway station. The quality of the work is obvious - but the thought that has gone into the way the spaces are programmed is what blew me away. Where this library really breaks new ground is with the 8 labs within the building ${ }^{2}$. They are the DigiLab, GameLab, FutureLab,

2 More correctly, there are six labs: DigiLab, GameLab, FutureLab, FoodLab, TimeLab and WordLab and two additional spaces, the Kennismakerij/LearningLab and Stemmingmakerij/ DialogueLab 
Mobile FoodLab, LearningLab, TimeLab, DialogueLab, and WordLab. These are spaces to share, to learn, to think, to talk, to imagine. Each of the labs has a dedicated staff member to program the space, build partnerships and deliver programmes. What was obvious was that these labs just didn't spring up from the new building. Like Aarhus, they have been planning, designing, prototyping these concepts in their old library, but now they are able to make them visible and more accessible (Mackenzie 2019).

Peter Kok, Director of the Library in Tilburg has said:

Traditionally, the book and collection have been at the center of libraries, then came the time when everything revolved around the customer, but now we mainly want to connect people, facilitate interaction and the sharing of knowledge and stories in order to make a difference. That is why we want as few thresholds as possible (Civic Architects 2019, 33).

\section{The Labs at LocHal}

The labs at LocHal are particularly innovative and support the library's aims of engagement, inclusion, interaction with knowledge, creativity and learning. In the DigiLab, young and old experiment with new media and the latest hi-tech hardware and software, editing photos and videos, programming robots, having virtual reality experiences or creating games. There are 3D printers and cutting-edge facilities like a green screen for photography and film. The DigiLab is for innovators as well as digital illiterates.

The GameLab is an open space for gamers, e-sporters and supporters. In the oval futuristic space, the newest consoles and PCs are available alongside retro equipment and a diverse collection of board games. The GameLab offers space for table-top games and roleplaying games. Gamers can improve their skills, organise events, learn about design, collaborate and inspire each other. Besides leisure and learning, the lab offers gamers, their parents and professionals, information on responsible gaming and educational opportunities.

The FoodLab is for food lovers, local entrepreneurs and innovators, and suits all tastes. There is always something to taste, smell, see or feel. But there is also food for thought. During food events people can learn about what is being served, including nutritional value, origin and the innovative technologies behind its creation.

The FutureLab provides the opportunity for Tilburg residents to talk and think about the city ten years from now. Together with experts they can design and participate in citizen science projects focused on technological and social innovation, climate issues and sustainable living. A large digital screen spanning 
the entire width of the wall shows environmental and civic data about the city which can lead to discussion and action.

In the TimeLab, the past, present and future of the city of Tilburg are presented. Not only does this space hold the library's special Tilburg Collection, but it also displays objects, photographs and films about the city's heritage. Local traditions and rituals are demonstrated, discussed and celebrated.

The WordLab is an incubator and meeting place for lovers of language, literature and creative writing. The walls and ceiling are crowded with books and the intimate space at the top of the LocHal houses the extensive linguistics and literature collection.

\section{Special Spaces}

The role of the KennisMakerij/Learning or Knowledge-making area (Figure 7) in the former library in generating ideas and approaches for the new LocHal has already been mentioned. It continues in LocHal on the first floor and features two performance stages built from old books stacked in varying heights and topped with an oak platform. During gatherings, lectures or performances, people can sit on the staircase connecting the first and second floors with the open seating facilitating discussion during presentations and debates.

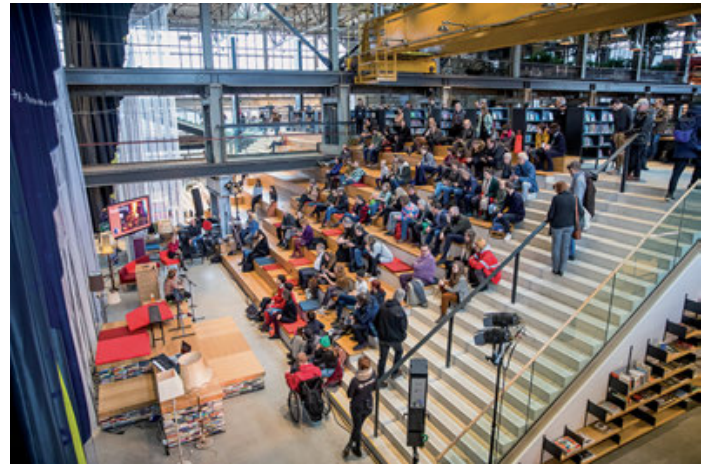

Fig. 7: KennisMakerij/Learning or Knowledge-making area.

(C) Lieselotte Port.

The StemmingMakerij/Dialogue or Discussion forum space is for people who want to make their voices heard. The quirky round benches accommodating sixty people can be configured in different ways. A curtain of strings as colourful as the rainbow itself is hung on the acoustic and glass walls and symbolises soci- 
ety's diversity. The café can easily be spotted by passengers in passing trains and houses a distinctive bar bearing a large, illuminated LocHal logo.

The LocHal tracks are still visible in the concrete floor and have gained a new lease on life in being used to move three large tables, each supported by an old train chassis. A single table can become the extension of the bar in the café; the tables when placed together form a stage or catwalk; they can be moved outside along the tracks to form a stage for events on the square. Kunstloc Brabant and the library work together on a programme to display the works of local artists and to bring art and culture to the attention of visitors.

An interior street crosses the building drawing attention to the historic industrial columns which retain vestiges of their past life. The columns are fitted with wooden tables and lighting, becoming places for reading and studying. Bookcases flank the street and mobile display units present specific book collections shelved with covers facing out as in a bookshop. Books are borrowed on the street with a large bookcase forming a wall for the office and providing a balance between privacy and connection.

The nearby Efteling theme park is the source of inspiration for the children's library (Figure 8). Bookcases resemble coloured pencils and rulers, and giant fairy tale books line a walkway and encourage play. Small children read at tables shaped like mobile phones or listen to storytelling sessions while lying on a giant open book. Seating features playful letters in the form of fairy tale animals.

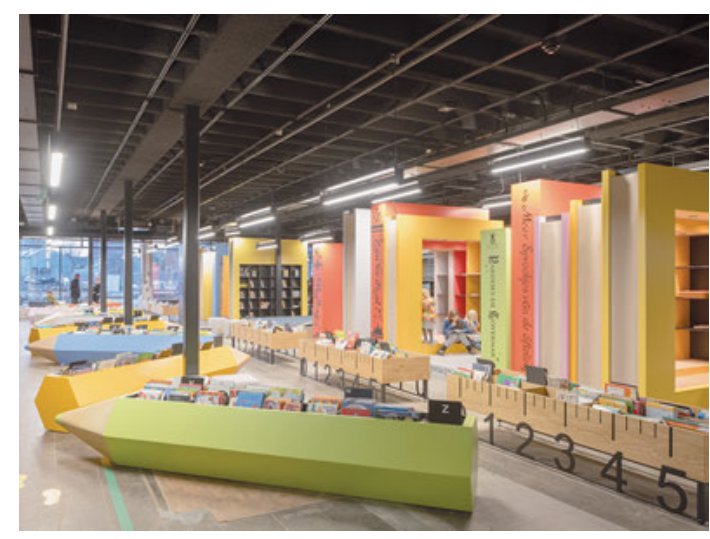

Fig. 8: Children's library. (c) Ossip Architectuurfotografie. 


\section{Sustainability}

The LocHal design optimises the features of the existing building. The motto adopted was "Work with what you have". The adaptive strategy applied to the architecture, the structural system, climate control and energy use. Much of the elegant industrial building was conserved. The new design is a contemporary reinterpretation of the late-industrial building and builds on the logic of the original design. The new structure is a hybrid system. The full load-bearing strength of the original floors and beams, designed to support heavy locomotives, is used for the new floors. Climate control also follows a hybrid model with the degree to which an area in the building has artificial climate control depending entirely on its function. Adjusting to the people not the space was the principle applied. An ingenious system of five separate climate zones ensured that physical adaptations could be kept to a minimum, transforming the LocHal building into one large usable volume with efficient energy usage.

\section{Conclusion}

The LocHal has been applauded by many (Van Leeuwen 2019) and won multiple awards. It was shortlisted for the IFLA/Systematic Public Library of the Year award and winner of the World Building of the Year 2019 at the World Architecture Festival. LocHal has won many other awards for creative reuse, best building, liveability and social cohesion, interior design, habitat, rebirth and conservation from various professional associations and organisations.

The LocHal is a perfect match for the people of Tilburg, reflecting the community and its needs. Tilburg is an entrepreneurial city, where people work, create and innovate. It is a city where bottom-up initiatives are stimulated and supported. The LocHal invites all individuals, entrepreneurs, innovators, creators and makers to share their knowledge, stories and ideas so that others can become inspired, learn and contribute. LocHal has been described as the living room of the city (Stevens 2019). One columnist has taken the analogy even further: "For Tilburg residents, it's also becoming the dining room, the kitchen, the garden shed and the corridor - that's what happens when, through insider nods and spatial flexibility, people develop a sense of ownership of their social spaces" (Messina 2019). LocHal is a unique learning and working environment, where both young and old are challenged to take new roads, to make unexpected connections, and to experiment, think and act freely. LocHal is a place where community members translate worldwide societal issues, like the UN Sustainable Development Goals, 
into their own environment and contribute locally to find solutions. LocHal is a place where Tilburgers live a life rich in knowledge and inspiration, together.

\section{References}

Civic Architects. 2019. “LocHal Public Library - Civic Architects.” Issuu, June 17, 2019. https// issuu.com/civicarchitects/docs/2019_04_23_-_lochal_tilburg_-_prese

Lomholt, Isabelle. 2020. "LocHal Library in Tilburg: Community Building Development in Holland.” E-architect, January 27, 2019. Updated March 29, 2020. https://www.e-architect. co.uk/holland/lochal-library-in-tilburg

Mackenzie, Christine. 2019. "The Evolution of the Public Library - from Frankston to Tilburg." Christine Mackenzie Librarian President IFLA International Federation of Library Associations and Institutions [Blog], February 5, 2019. https://www.christinemackenzie. com.au/post/2019/02/05/the-evolution-of-the-public-library-from-frankston-to-tilburg

Messina, Rab. 2019. "A Dutch City Gets a New Public Living Room - And So Much More.” Frame, February 8, 2019. https://www.frameweb.com/article/a-dutch-city-gets-a-new-publicliving-room-and-so-much-more

Stevens, Philip. 2019. "Vast Locomotive Hall in the Netherlands is Transformed into Tilburg's 'New Living Room'.” Designboom, January 16, 2019. https://www.designboom.com/ architecture/lochal-library-tilburg-netherlands-01-16-2019/

Van Leeuwen, Abuzer. 2019. "The LocHal in Tilburg: How an Old Building is Transformed into a Spectacular New Library.” DutchReview, December 23, 2019. https://dutchreview.com/ cities/tilburg/lochal-transformed-into-spectacular-new-library/ 